\title{
Effects of Segmental Stabilization in Patients with Low Back Pain: Systematic Review
}

\author{
Rayane Kallyne Berto Do Nascimento', Sillwe Capitulino Farias Costa', Thiani Sousa Sales', \\ Rodrigo Marcel Valentim da Silva',2,3
}

\begin{abstract}
Background: Low back pain is a problem that affects a large part of the population, about $80 \%$, reaching people with greater constancy in the period of higher productivity. For the treatment of this condition there are several physiotherapeutic techniques, among them the segmental stabilization is specific exercises for the stabilizing muscles of the lumbar spine, aiming at a better control and activation of the deep muscles. Methods: A systematic review was performed through the PubMed, Scielo, Google academic, Bireme and Medline databases. Results: After the search, the results show that the segmental stabilization exercises reduced pain, as well as improved functional capacity. Conclusion: Segmental stabilization exercises proved to be an efficient proposal for the treatment of low back pain, showing efficacy both in pain and in improving functional capacity.
\end{abstract}

Keywords: Low Back Pain. Exercises. Exercise Therapy. Lumbar Stabilization. Physiotherapy.

\section{INTRODUCTION}

According to the World Health Organization around 80\% of people will suffer at least one episode of back pain during their lifetime. It is perceived that the data cited above are high and worrying, thus requiring preventive actions and at the same time treatment modalities that are effective and that contribute to an improvement of this morbidity so recurrent in people's lives. LBP is explained as a set of signs and symptoms in which the main manifestation is the painful sensation focused in the lower compartment of the spine causing decay of functionality. It is believed that mechanical LBP, i.e., in resting situations, the pain is alleviated and with movement is observed an accentuation of pain is the most diligent condition, about $80 \%$ of the assessed facts ${ }^{(1-3)}$.

The appearance of LBP sometimes has multifactorial characteristics. The literature describes a large number of causal factors of LBP, such as age, gender, obesity, smoking, physical conditioning, occupation, psychosocial causes, among others. LBP reaches people more consistently in the period of higher productivity. Thus, LBP brings with it a high problem for the public health system, since the values spent on diagnoses, treatments and early departure from work leads to a tax burden on society ${ }^{(4-6)}$.

The treatment of LBP may be conservative or surgical, however, it should always be taken into account the first alternative, with the use of medications associated with multidisciplinary rehabilitation programs. During the literature review it was found two studies that aimed to know the effectiveness of physical therapy resources applied in cases of LBP. One study used pulsatile radiofrequency and the other used pilates. Both were effective in reducing pain. Another study was done with two types of physiotherapeutic interventions called Back School and Mckeinze methods and concluded that both methods had relevant benefits on the treatment of chronic nonspecific LBP(7-9).

It is remarkable the great number of techniques and procedures used by physiotherapy for the treatment of LBP. In the midst of numerous interventions there is the definition of lumbar segmental stabilization, in order to strengthen the lumbar region, and thus to benefit from its composition of overspending. In the seventies it was the moment in which the stabilization of the segments of the spine began to be questioned and then to be used as a type of physiotherapeutic intervention for the treatment of LBP. These exercises are tenuous, exclusive and accurate, reducing the possibility of generating pain or inhibitory reflexes. Some muscles reported in the literature such as multifidus, transverse abdomen and lumbar square and also structures as the pelvic floor are closely interconnected with lower back pain. It is also necessary to know the muscles responsible for segmental stabilization for a better understanding, development and application of these exercises $^{(10,11)}$. 
Segmental stabilization does not jeopardize the injured components, leaving the spine in a neutral posture, favoring a better acceptance and adaptation of the individual to the exercises. In another study they used this technique on mechanical postural LBP with 12 women and found that the exercise program showed positive results in pain reduction and also in functional disability. It was applied Vertebral Segmental Stabilization in patients with lumbar disc herniation and concluded that the technique brought pain relief, as well as improved musculature control and expansion of the multifidus muscle tropism ${ }^{(11-13)}$.

It is known that one of the risk factors related to the onset of LBP is the weakness of the superficial and deep muscles of the lumbar region. In this way the application of segmental stabilization is an alternative treatment for this condition, since its exercises can cause the individual to regain a greater activation of the weakened muscles, increasing the local proprioception and leading to the maintenance of muscle contraction. In addition, many patients with LBP eventually lose functional capacity due to pain and the segmental stabilization exercises reduce pain and increase patients' ability to perform movements required for daily activities ${ }^{(14)}$. The objective of this study was to investigate in the literature the effects of segmental stabilization in patients with LBP.

\section{METHODS}

This study is a systematic review, in which the inclusion criteria chosen were studies of the experimental type published in the English, Spanish and Portuguese from 2008 to 2016. Exclusion criteria were studies in which the number of subjects participating in the studies did not reach at least 20 subjects and also literature reviews. It was used articles electronically available on the internet in the PubMed, Scielo, Google academic, Bireme and Medline database. The keywords were "LBP; exercises; exercises therapy; lumbar stabilization; physiotherapy". Some keywords were used together to broaden the search (Figure 1).

\section{RESULTS}

Table 1 describes the type of study, population and sample and the used evaluation instruments.

Table 1 shows that most of the studies recruited patients with chronic LBP. It also shows that the most used evaluation instruments were the visual analogue scale, followed by the Oswestry Disability Index.

Table 2 shows the procedures and statistical analysis.

Table 2 shows that in three studies the duration of treatment totaled six weeks, two studies lasted eight weeks and only one study lasted four weeks. Most of the groups

Table 1: Methodological characteristics of the study type, population and methods of analysis.

\begin{tabular}{|c|c|c|c|}
\hline Author & Study type & Population - Sample & Evaluation instruments \\
\hline França et al; 2010 & Randomized clinical trial & $\begin{array}{l}30 \text { patients with CLBP divided into } \\
2 \text { groups ( } 4 \text { men e } 11 \text { women in each) }\end{array}$ & $\begin{array}{l}\text { VAS, McGill Pain Questionnaire, } \\
\text { Oswestry Disability Index; Pressure } \\
\text { Biofeedback Unit - PBU }\end{array}$ \\
\hline Bellosta et al; 2011 & Randomized clinical trial & $\begin{array}{l}37 \text { with LBP associated with } \\
\text { menstruation in women with associated } \\
\text { lumbar hypermobility divided into } \\
2 \text { groups: intervention group }(n=19) \text { and } \\
\text { control group }(n=18)\end{array}$ & $\begin{array}{l}\text { Oswestry Disability Index, VAS, } \\
\text { exploratory tests of the articulation of } \\
\text { the lumbar segment }\end{array}$ \\
\hline Hosseinifar et al; 2013 & Randomized clinical trial & $\begin{array}{l}30 \text { patients were randomized into } \\
2 \text { groups: segmental stabilization } \\
\text { exercise group }(n=15) \text { and McKenzie } \\
\text { exercise group }(n=15)\end{array}$ & $\begin{array}{l}\text { VAS, Functional Reading Independence } \\
\text { (FRI) Index and thickness measurement } \\
\text { of transverse abdominal and multifidus } \\
\text { muscles using ultrasound }\end{array}$ \\
\hline Moom et al; 2013 & Randomized clinical trial & $\begin{array}{l}21 \text { patients with non-specific CLBP } \\
\text { divided into } 2 \text { groups: lumbar } \\
\text { stabilization exercise group }(n=11) \text { and } \\
\text { lumbar dynamic strengthening exercise } \\
\text { group }(n=10)\end{array}$ & $\begin{array}{l}\text { VAS, Oswestry Disability Index and } \\
\text { intensity of lumbar extensors measured } \\
\text { at various angles from } 0 \text { to } 72 \text { degrees } \\
\text { at } 12 \text {-degree intervals using MedX }\end{array}$ \\
\hline Jeong et al; 2015 & Randomized clinical trial & $\begin{array}{l}40 \text { women with CLBP divided into } \\
2 \text { groups of } 20 \text { women: one group } \\
\text { performed lumbar stabilization exercise } \\
\text { and exercise to strengthen the gluteal } \\
\text { muscles and the other group performed } \\
\text { lumbar stabilization exercise }\end{array}$ & $\begin{array}{l}\text { Oswestry Disability Index, } \\
\text { Measurement of lumbar isometric } \\
\text { muscle strength, was used equipment } \\
\text { to measuring M3 muscle strength and } \\
\text { to examine balance was used a Tetrax }\end{array}$ \\
\hline Woo; Kim, 2016 & Double-blind, randomized clinical trial & $\begin{array}{l}30 \text { patients with CLBP divided into } \\
2 \text { groups: lumbar stabilization exercise } \\
\text { with } 15 \text { patients (group A); lumbar } \\
\text { stabilization exercise and thoracic } \\
\text { extension exercises (group B) with } \\
15 \text { patients }\end{array}$ & $\begin{array}{l}\text { Evaluation of the lumbosacral } \\
\text { alignment through lateral radiographs } \\
\text { of the lumbosacral spine and Oswestry } \\
\text { Disability Index }\end{array}$ \\
\hline
\end{tabular}


in which the segmental stabilization exercises were applied focused on the contraction of the transverse abdominal and multifidus muscles. In two studies the frequency of exercises was performed daily.

Keywords: Low back pain. Exercises. Exercises therapy Lumbar stabilization. Physiotherapy

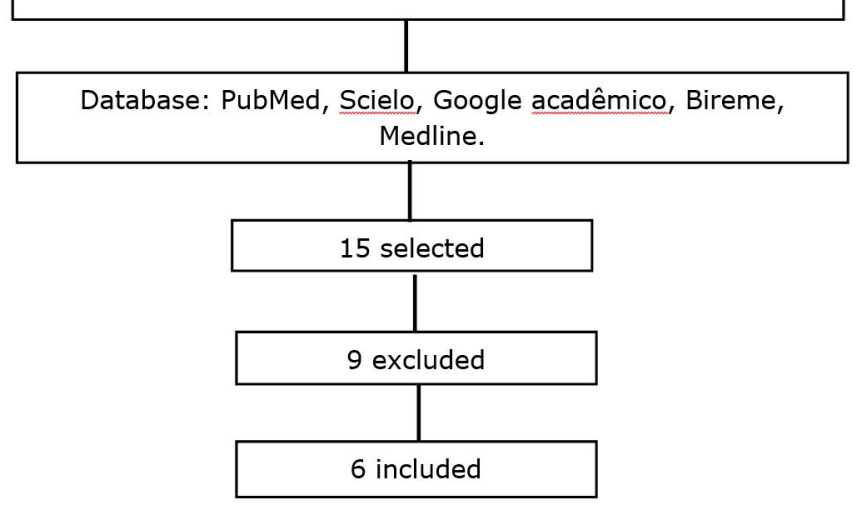

Figure 1. Flowchart of selection of the articles.
Table 3 describes the results and the conclusion of the studies.

Table 3 shows that in most studies segmental stabilization resulted in a greater advantage in the items evaluated, such as pain and functional disability, with a higher statistical significance. In most of the studies it is concluded that the segmental stabilization is superior to another treatment proposal and is indicated for the treatment of patients with LBP.

\section{DISCUSSION}

The results point to several findings relevant to the study, mainly related to LBP. The weakness of the deep muscles of the lumbar region influences the onset of pain in this region, together with the weakness of the superficial musculature. Thus, in the study, the segmental stabilization exercises were used in one group and the other group performed exercises to strengthen the superficial muscles of the abdomen and trunk. It was observed at the end of the study that the pain significantly reduced in the group that performed the

Table 2. Procedures and Statistical Analysis.

\begin{tabular}{cl}
\hline \multicolumn{1}{c}{ Author } & \multicolumn{1}{c}{ Procedure } \\
\hline & SS Group: exercises focused on TrA and lumbar multifidus; \\
ST Group: Strengthening exercises focused on the rectus \\
abdominis, internal and external oblique and erector \\
spinae. 6 weeks and 30min sessions, 2 times a week, \\
3 sets of 15 repetitions for each exercise.
\end{tabular}

Intervention Group: Home program of isometric exercises with simultaneous contraction of the transverse abdominal, multifidus and pelvic floor muscles, divided into 5 levels of progressive difficulty during 8 weeks, daily from Monday to Friday. Control group: was performed no intervention

Training program consisted of 18 supervised individual training sessions for both groups, 3 times a week for

Hosseinifar et al; 20136 weeks. Each training session lasted an hour. Segmental stabilization exercises group performed 6 exercise sets and exercises group performed 6 exercises

Exercises were performed for 1 hour, twice a week, for 8 weeks. Lumbar stabilization exercise group $(n=11)$ with 16 exercises, aiming to strengthen the deep lumbar stabilizers and group of conventional dynamic strengthening exercises $(n=10)$ with 14 exercises, which activated flexor and extensor muscle groups

The same lumbar segmental stabilization exercise was applied to both groups and exercise to strengthen the hip

Jeong et al; 2015 muscles was added to the SMG + LSE group. All subjects performed their respective exercise 3 times a week (for 50min per day) every 2 days for 6 weeks.

Group B: lumbar stabilization exercises and chest extension exercises (15min each). Group A: lumbar stabilization exercises (30min), 5 times a week for 4 weeks.

\section{Statistical Analysis}

One-Way ANOVA was used for intergroup and intragroup comparisons. For the TrA activation was used the binomial test. The analyzes were done using Minitab 14 and 15 for Windows. The level of significance was set at $5 \%$.

SPSS 15.0 used to data analysis. Kolmogorov-Smirnov test used to verify the values of the quantity variables. Student's t test for independent samples. Mann-Whitney test if the values distribution was significantly different from normal. In the qualitative variables was used the Fisher's exact test. Student's t test used for variables whose values did not present significant differences. Wilcoxon test if the distribution of values was significantly different from normal

Data were analyzed using SPSS version 17 . They were tested for normal distribution using the Kolmogorov-Smirnov test. The independent samples t-test was used to compare Mckenzie and stabilization groups. The paired t-test was used to compare the variables before and after the training in each group.

Fisher's exact test used to differentiate general characteristics. Mann-Whitney $U$ test used to analyze differences in means. Mean values were compared to mean values after treatment within the groups using the Wilcoxon test. Mann-Whitney $U$ test to compare maximal isometric strength, visual analogue scale and ODI score between the 2 groups. All statistical analyzes were performed using SPSS version 18 .

Statistical data, means and standard deviations of all data were calculated using PASW Statistics 18.0 for Windows. Paired t-test used to examine changes in lumbar disability, lumbar muscle strength, and balance before and after the experiment within each group. Independent t test to compare homogeneity and changes between groups.

The independent t-test was used to perform a homogeneity analysis between the groups before and after the intervention and the paired t-test was used to analyze changes in variables before and after exercise. PASW for Windows was used for statistical analysis. 
Table 3. Results and conclusion of the studies.

\begin{tabular}{|c|c|c|}
\hline Author & Results & Conclusion \\
\hline França et al; 2010 & $\begin{array}{l}\text { Both treatments were effective in relieving pain and improving } \\
\text { disability }(p<0.001) \text {. Those in the SS group had more significant gains } \\
\text { for all variables when compared to the ST group }(p<0.001) \text {, including } \\
\text { Abdominal Transversal activation, in which the relative gains were } 48.3 \% \\
\text { and }-5.1 \% \text {, respectively }\end{array}$ & $\begin{array}{l}\text { Both techniques attenuated pain and reduced } \\
\text { disability. Segmental stabilization is superior } \\
\text { to superficial strengthening for all variables. } \\
\text { The superficial reinforcement does not improve the } \\
\text { Abdominal Transverse activation capacity. }\end{array}$ \\
\hline Bellosta et al; 2011 & $\begin{array}{l}\text { Although differences between groups did not reach statistical } \\
\text { significance, the intervention group showed greater differences with } \\
\text { statistically significant improvement of pain, before }(p<0.01) \text { and during } \\
\text { menstruation }(p<0.04) \text {. }\end{array}$ & $\begin{array}{l}\text { A home lumbar stabilization exercise program can } \\
\text { reduce LBP associated with menstruation in women } \\
\text { with segmental lumbar hypermobility. }\end{array}$ \\
\hline Hosseinifar et al; 2013 & $\begin{array}{l}\text { After interventions, the pain score decreased in both groups. } \\
\text { The disability score decreased only in the stabilization group. } \\
\text { The thickness of the left multifidus increased significantly during the } \\
\text { states of rest and contraction in the stabilization group. The thickness of } \\
\text { the right transverse abdomen during the abdominal stretch maneuver } \\
\text { and the left transverse abdomen thickness during the active maneuver } \\
\text { of right leg elevation were significantly increased in the stabilization } \\
\text { group. Pain intensity, disability score, right transverse abdomen } \\
\text { thickness during abdominal stretch maneuver, and left transverse } \\
\text { abdomen thickness during active right leg elevation in the stabilization } \\
\text { group were greater than those of Mckenzie }\end{array}$ & $\begin{array}{l}\text { Stabilization exercises are more effective than } \\
\text { McKenzie exercises in improving pain intensity and } \\
\text { function score and increasing the thickness of the } \\
\text { transverse abdomen. }\end{array}$ \\
\hline Moom et al; 2013 & $\begin{array}{l}\text { Comparing the baseline, the lumbar extension force at all angles } \\
\text { improved significantly in both groups after } 8 \text { weeks. Significantly greater } \\
\text { improvements in the lumbar stabilization exercise group at } 0 \text { and } 12 \text { of } \\
\text { lumbar flexion. Visual Analogue Scale decreased significantly after } \\
\text { treatment. However, the changes were not significantly different } \\
\text { between groups. Oswsestry scores improved significantly only in the } \\
\text { stabilization exercise group. }\end{array}$ & $\begin{array}{l}\text { Both lumbar stabilization and the dynamic } \\
\text { strengthening exercise strengthened lumbar } \\
\text { extensors and reduced LBP. However, the lumbar } \\
\text { stabilization exercise was more effective in } \\
\text { strengthening the lumbar extensor and functional } \\
\text { improvement in patients with chronic non-specific } \\
\text { LBP. }\end{array}$ \\
\hline Jeong et al; 2015 & Each evaluation item showed a statistically significant effect. & $\begin{array}{l}\text { The clinical application of exercise in this study } \\
\text { showed that the lumbar segmental stabilization } \\
\text { exercise + exercise to strengthen the gluteal } \\
\text { muscles resulted in greater decrease in the index } \\
\text { of LBP incapacity and increased muscle strength } \\
\text { and lumbar balance than the lumbar segmental } \\
\text { stabilization exercise in patients with chronic LBP } \\
\text { receiving exercise treatments during the same } \\
\text { period. }\end{array}$ \\
\hline Woo; Kim, 2016 & $\begin{array}{l}\text { Both groups showed improvement in lumbosacral alignment and } \\
\text { disability index. Group B showed greater changes in the lordotic angle } \\
\text { and in the Oswestry disability index than in group A, although the } \\
\text { differences were not statistically significant. }\end{array}$ & $\begin{array}{l}\text { The lumbar stabilization exercise with chest } \\
\text { extension exercise may be recommended for } \\
\text { improvement of chronic LBP, although the } \\
\text { improvements observed in lumbosacral alignment } \\
\text { and the LBP index in this study have not reached } \\
\text { statistical significance. }\end{array}$ \\
\hline
\end{tabular}

segmental stabilization exercise, about 99\% evaluated by VAS. Both groups also demonstrated improvement in functional capacity. Based on the other group, pain also decreased, but it was not superior to the stabilization group. It was also observed that the segmental stabilization group it increased the contraction capacity of the transverse abdominal muscle $\mathrm{e}^{(14)}$.

It is believed that the greatest reduction in pain levels in the stabilization group occurred due to the fact that stabilization exercises cause changes in the mechanisms of muscle contraction of the transverse abdominal muscle, because in the stabilization group the level of contraction increased about $48.3 \%$, unlike the strengthening group in which the contraction of the abdominal transverse showed negative results worsening in about $-5.1 \%$. This study presents limitations that must be considered, since the patients did not perform follow-up examinations during the intervention period.

Compared to another study that used segmental stabilization exercises in association with the strengthening of gluteal muscles, the combination of the two interventions resulted in a greater reduction in disability in LBP, as well as improvement in the strength and balance of the lumbar region instead of only the use of segmental stabilization. This result can be explained because the muscles of the gluteal region are close to structures interconnected with the lumbar region, since the fifth lumbar vertebra connects directly over the sacrum and, consequently, the muscles of the gluteus when strengthened, offer support in the lumbar stabilization due to the close proximity between the structures ${ }^{(15)}$. 
The study of Jeong et al., also presents limitations that should not be disregarded, since the study population were only women and the authors affirm that the sample was small. Another study conducted by Moom et al., which used an intervention based on segmental stabilization and another with dynamic strengthening, the segmental stabilization exercise were more effective in reducing functional disability, such conclusion resembles the study of França et al ${ }^{(15-16)}$.

The reduction of pain and the improvement of the functionality was also evident in the study of Hosseinifar et al., in which the segmental stabilization exercises significantly reduced the indices evaluated when compared to the Mckenzie exercises. The improvement in the pain variable was also observed in the study of Bellosta et al., which used the stabilization exercises in 19 women and a control group. The pain indexes despite being reduced in the stabilization group were not as expressive as the studies of França et al.; Hosseinifar et al.; Moom et al.; Jeong et al. What may have interfered with the outcome of the study is that the exercises were not supervised directly because the exercise program was performed at home and we believe that the absence of monitoring during the exercise may have influenced the outcome ou-18). $^{(14)}$

As in the study of Jeong et al., the study conducted by Woo et al., 2016, used an association of two types of exercises in one group and the other only the segmental stabilization. The results were that the treatment proposals in both groups reduced the functional disability index. The study also presents some limitations as, for example, it was the only study in which the program period lasted only four weeks. The addition of another intervention in conjunction with the segmental stabilization exercises may have masked the final result of both studies. However, as was well established in other studies, the use of segmental stabilization in a single way contributed to a decrease in pain, in addition to the improvement of other conditions evaluated, such as the functional disability index (França et al.; Hosseinifar et al.; Moom et al.). It can be understood from these studies that the intervention in patients with LBP using the segmental stabilization exercises offers a good perspective for a greater use of these exercises. However, some studies end up adding to the segmental stabilization program other types of exercise, which may conflict with the real effects of the segmental stabilization exercises ${ }^{(14-19)}$.

With regard to methodological quality, it is believed that the inclusion and exclusion criteria defined by the studies were successful, because they sought to recruit patients that actually corresponded to the expectations of the programs. The duration of the programs was also reasonable, since the majority exceeded the period of one month. Another advantage is that the experimental studies make possible to find new treatment strategies that seek to increase the knowledge of new practices, thus favoring the treatment of patients. Clinical practice may benefit from the results, because studies have shown that the application of segmental stabilization in patients with LBP resulted in improved pain, functional capacity, increased capacity of activation of the deep musculature, among other relevant findings.

\section{CONCLUSION}

According to the present study we can infer that the instability of the lumbar segment is one of the factors related to LBP. In addition, segmental stabilization exercises have been shown to be an efficient proposal for the treatment of LBP because they are exercises that act directly on the mechanisms involved with the stabilization of the lumbar segments and that their applicability in clinical practice should be stimulated due to positive results with regard to pain and improvement of functional capacity. However, further studies are needed to follow patients after the intervention period to assess whether segmental stabilization exercises maintain their long-term effects.

\section{AUTHORS' CONTRIBUTIONS}

RKBN and SCFC conducted a systematic review from the search of the descriptors, database selection, choice of articles to the writing of the manuscript. RMVS conducted the guidance of the authors mentioned above, and together with TSS performed the critical intellectual review of the manuscript. All authors read and approved the final manuscript.

\section{CONFLICT OF INTEREST}

The authors declare that there was no conflict of interest.

\section{AUTHORS DETAILS}

2 Universidade Federal Rio Grande do Norte (UFRN), Natal (RN), Brasil.

${ }^{3}$ Faculdade Estácio do Rio Grande do Norte, Natal (RN), Brasil.

\section{REFERENCES}

1. Gouveia KMC, Gouveia EC. O músculo transverso abdominal e sua função de estabilização da coluna lombar. Fisioter Mov, v. 21, n. 3, p. 45-50, 2008.

2. Morales MIC, Queraltó JM, Fernández JV. Etiología, cronificación y tratamiento del dolor lumbar. Clínica y Salud, v. 19, n. 3, p. 379-392, 2008.

3. Aguilera A, Herrera A. Lumbalgía: una dolencia muy popular y a la vez desconocida. Comunidad y Salud. 2013;11(2):80-9.

4. Joaquim AF. Initial approach to patients with acute lower back pain. Joaquim aF 188 Rev assoc med BRas. 2016;62(2):188-91.

5. Silva RMV, Lima MS, Costa FH, Silva AC. Efeitos da quiropraxia em pacientes com lombalgia: uma revisão sistemática. Effects of chiropractic in patients with low back pain:a review systematic . 10(84):105-10.

6. Furtado RNV, Ribeiro LH, Abdo BA, Descio FJ, Junior CEM, Serruya DC. Dor lombar inespecífica em adultos jovens: fatores de risco associados. Rev Bras Reumatol. 2014;54(5):371-7.

7. Souza AJ De, Morete MC. O uso da radiofrequência pulsátil no tratamento da dor lombar Rev. dor. 2012;13(2):165-9.

8. Miyamoto GC, Costa LOP, Cabral CMN. Efficacy of the Pilates method for pain and disability in patients with chronic nonspecific low back pain: a systematic review with meta-analysis. Brazilian J Phys Ther. 2013;17(6):517-32.

9. Garcia AN, Gondo FLB, Costa RA, Cyrillo FN, Costa LOP. Efeitos de duas intervenções fisioterapêuticas em pacientes com dor lombar crônica não-específica: Viabilidade de um estudo controlado aleatorizado. Rev Bras Fisioter. 2011;15(5):420-7. 
10. Santos RM, Freitas DG, Pinheiro ÍCO, Vantin K et al. A RTIGO DE REVISÃO Estabilização Segmentar lombar Lumbar segmental stability. Med Reabil. 2011;30(1):14-7.

11. França FJR, Burke TN, Claret DC, Marques AP. Estabilização segmentar da coluna lombar nas lombalgias: uma revisão bibliográfica e um programa de exercícios. Fisioter e Pesqui. 2008;15(2):200-6.

12. Pereira NT, Ferreira LAB, Pereira WM. Efetividade de exercícios de 1. estabilização segmentar sobre a dor lombar crônica mecânico-postural. Fisioter em Mov. 2010;23(4):605-14.

13. Siqueira GR, Alencar GG, Oliveira NK, Leite FNT de S. Eficácia da estabilização segmentar vertebral no aumento do trofismo dos multífidos em portadores de hérnia discal lombar. R Bras Ci e Mov. 2014;22(1):81-9.

14. França FR, Burke TN, Hanada ES, Marques AP. Segmental stabilization and muscular strengthening in chronic low back pain: a comparative study. Clinics. 2010;65(10):1013-7.

15. Jeong UC, Sim JH, Kim CY, Bo GH, Nam CW. The effects of gluteus muscle strengthening exercise and lumbar stabilization exercise on lumbar muscle strength and balance in chronic low back pain patients. J Phys Ther Sci. 2015;27(12):3813-6.

16. Moon HJ, Choi KH, Kim DH, Kim HJ, Cho YK, Lee KH, et al. Effect of lumbar stabilization and dynamic lumbar strengthening exercises in patients with chronic low back pain. Ann Rehabil Med. 2013;37(1):110-7.

17. Hosseinifar M, Akbari M, Behtash H, Amiri M, Sarrafzadeh J. The Effects of Stabilization and Mckenzie Exercises on Transverse Abdominis and Multifidus Muscle Thickness, Pain, and Disability: A Randomized Controlled Trial in NonSpecific Chronic Low Back Pain. J Phys Ther Sci. 2013;25(12):1541-5.

18. Bellosta MLZ, Montejo VM, Celis CL, López MEB, García CH, et al. Efectividad de un programa domiciliario de ejercicios de estabilización sobre el dolor lumbar asociado a la menstruación en mujeres con hipermovilidad. Fisioterapia. 2011;33(3):98-104.

19. Woo SD, Kim TH. The effects of lumbar stabilization exercise with thoracic extension exercise on lumbosacral alignment and the low back pain disability index in patients with chronic low back pain. J Phys Ther Sci. 2016;28(2):680-4. 